\title{
Contents, Vol. 9, 1975
}

\section{No. 1}

Mikx, F. H. M.; Hoeven, J. S. van der; Plasschaert, A. J. ML, and König, K. G.

(Nijmegen): Effect of Actinomyces viscosius on the Establishment and Symbiosis of Streptococcus mutatis and Streptococcus sanguis in SPF Rats on Different Sucrose Diets 1

Dewar, M. D. and Walker, G. J. (Sydney): Metabolism of the Polysaccharides of Human Dental Plaque. I. Dextranase Activity of Streptococci, and the Extracellular Polysaccharides Synthesized from Sucrose 21

Groeneveld, A. and Arends, J. (Utrecht): Influence of $\mathrm{pH}$ and Demineralization Time on Mineral Content, Thickness of Surface Layer and Depth of Artificial Caries Lesions 36

Magrill, D. S. (Betchworth): Influence of Fluoride on the Rate of Dissolution of Hydroxyapatite in Acidic Buffer Solution 45

Wei, S. H. Y. and Schulz, E. M. jr. (Iowa City, Iowa): In vivo Microsampling of Enamel Fluoride Concentrations after Topical Treatments 50

Poulsen, S. and Larsen, M. J. (Aarhus): Dental Caries in Relation to Fluoride Content of Enamel in the Primary Dentition 59

Rölla, G. and Melsen, B. (Aarhus): Desorption of Protein and Bacteria from Hydroxyapatite by Fluoride and Monofluorophosphate 66 Gjermo, P.; Bonesvoll, P.; Hjeljord, L. G., and Rölla, G. (Aarhus): Influence of Variation of $\mathrm{pH}$ of Chlorhexidine Mouth Rinses on Oral Retention and Plaque-Inhibiting Effect 74

Menaker, L. and Navia, J. M. (Birmingham, Ala.): Caries Incidence in Well-Fed and Malnourished Rats Treated with Isoproterenol during Development 83 Short Communication Wegner, H. (Greifswald): Increment of Caries in Young Diabetics 91 No. 2

Announcements of the Board of ORCA 97

Geddes, D. A. M. (Newcastle upon Tyne): Acids Produced by Human Dental Plaque Metabolism in situ 98

Birkeland, J. M. (Oslo): In vitro Study of the Mechanisms of Action of Fluoride in Low Concentrations 110

Breuer, M. M. and Cussler, E. L. (Isleworth, Middlesex): Accelerating Mono fluorophosphate Uptake by Hydroxyapatite 119

Groeneveld, A.; Purdell-Lewis, D. J., and Arends, J. (Groningen): Influence of IV Contents

the Mineral Content of Enamel on Caries-Like Lesions Produced in Hydroxyethyl Cellulose Buffer Solutions 
Loesche, W. J.; Syde, S. A.; Murray, R. J., and Mellberg, J. R. (Barrington, 111.): Effect of Topical Acidulated Phosphate Fluoride on Percentage of Streptococcus mutans and Streptococcus sanguis in Plaque. II. Pooled Occlusal and Pooled Approximal Samples 139 Brook, A. H.; Gawthrope, J., and Winter, G. B. (Leatherhead, Surrey): Calcium Glycerophosphate and Dental Plaque. Clinical Pilot Study 156 Moore, W. J. and Corbett, M. E. (Birmingham): Distribution of Dental Caries in Ancient British Populations. III. The 17th Century 163

No. 3

Knuuttila, M. L. E. and Mäkinen, K. K. (Turku): Effect of Xylitol on the Growth and Metabolism of Streptococcus mutans 177

Fejerskov, O.; Silverstone, L. M.; Melsen, B., and Møller, 1. J. (Copenhagen): Histological Features of Fluorosed Human Dental Enamel 190

Luoma, H. (Helsinki): Participation of Phosphate of Bacterial Origin in the Phos phate Exchange and Rehardening of the Enamel and the Modifications by Fluoride, Chlorhexidine and Propanol 211

Tinanoff, N.; Wei, S. H. Y., and Parkins, F. M. (Iowa City, Iowa): Effect of the Acquired Pellicle on Fluoride Uptake in Tooth Enamel in vitro 224

Downer, M. C. (Manchester): Concurrent Validity of an Epidemiological Diagnos tic System for Caries with the Histological Appearance of Extracted Teeth as Validating Criterion 231

Short Communication

Keene, H. J.; Grossman, F. D.; Pederson, E. D.; Mellberg, J. R., and Nichol son, C. R. (Barrington, 111.): Caries Experience and Fluoride Concentration of Surface Enamel in Dental Fluorosis Patients 247

No. 4

Bowden, G. H.; Hardie, J. M., and Slack, G. L. (London): Microbial Variations in Approximal Dental Plaque 253

Takuma, S.; Ogiwara, H, and Suzuki, H. (Tokyo): Electron-Probe and Electron Microscope Studies of Carious Dentinal Lesions with a Remineralized Surface

Layer 278

Abstracts of Papers presented at the 21th ORCA Congress 186

No. 5

Ericson, T.; Sandham, J., and Magnusson, I. (Göteborg): Sedimentation Method for Studies of Adsorption of Microorganisms on to Apatite Surfaces in vitro 325 Contents V Carlsson, J.; Grahnen, H., and Jonsson, G. (Umeå): Lactobacilli and Strepto cocci in the Mouth of Children 333 Karjalainen, S. and Larmas, M. (Turku): Quantitative Study of the Arylaminopeptidase Activity in Normal and Altered States of Human Dentine 340 Ashley, F. P. (London): Calcium and Phosphorus Concentrations of Dental Plaque Related to Dental Caries in 11- to 14-Year-old Male Subjects Arends, J. and Schuthof, J. (Groningen): Fluoride Content in Human Enamel after Fluoride Application and Washing - An in vitro Study 363 
Silverstone, L. M.; Saxton, C. A.; Dogon, I. L., and Fejerskov, O. (London): Variation in the Pattern of Acid Etching of Human Dental Enamel Examined by Scanning Electron Microscopy 373

Jongebloed, W. L.; Molenaar, I., and Arends, J. (Groningen): Effect of Monofluorophosphate on the Pathways followed by Cariogenic Agents 388

Errata 404

Announcement of the Board of ORCA 404

No. 6

Newman, H. N. and Wilson, C. M. (Bristol): Thymidine and Thymine Uptake in Human Dental Plaque: an Autoradiographic Study 405

Saxton, C. A. (Isleworth): Determination by Electron Microscope Autoradiography of the Distribution in Plaque of Organisms that Synthesize Intracellular Polysaccharide in situ $\quad 418$

Wöltgens, J. H. M. (Amsterdam): Influence of Diphosphonates and Sodium Fluoride on the Development of Artificial Caries. I. Chemical Aspects 438 Wei, S. H. Y. (Iowa City, Iowa): Effect of Topical Fluoride Solutions on the Enamel Surface as Studied by Scanning Electron Microscopy 445 Pearce, E. I. F. and More, R. D. (Wellington): Uptake of Fluoride by Enamel from Monofluorophosphate Dentifrices 459 Announcements of the Board of ORCA 475 Indeces

Subject Index 476

Author Index 478 